\title{
PECULIARITIES OF STRUCTURE OF COATINGS OF Fe-Cr-Al SYSTEM FLUX-CORED WIRE PRODUCED UNDER CONDITIONS OF SUPERSONIC ELECTRIC ARC METALLIZATION
}

\author{
V.N. KORZHIK, A.L. BORISOVA, G.N. GORDAN, N.P. LYUTIK, A.A. CHAJKA and T.V. KAJDA \\ E.O. Paton Electric Welding Institute, NASU
}

11 Bozhenko Str., 03680, Kiev, Ukraine. E-mail: office@paton.kiev.ua

\begin{abstract}
To increase the efficiency of application of method of supersonic electric arc metallization (EAM) the investigations of structure and phase composition of coatings of flux-cored wire of the system $\mathrm{Fe}-\mathrm{Cr}-\mathrm{Al}$ were carried out in the frames of this work. Presented are the results of investigations of coatings produced by EAM method using the conventional and modified installation EM-14 and also installation PLAZER 15-SA for supersonic electric arc spraying. It is shown that use of supersonic gas jets at EAM allows significant improvement of coating quality, i.e. provides higher level of homogeneity and fine dispersion of structure (the thickness of lamellas is decreased from 10-30 to 5-10 $\mu \mathrm{m}$ ), decreases porosity by 3-5 times, decreases oxides content by $2-3$ times, $30-50 \%$ increases the hardness. The formation of solid solution of chromium and aluminium in iron with increased content of chromium at supersonic EAM is a precondition for ensuring the heat resistance of developed coatings of up to $1350{ }^{\circ} \mathrm{C}$, which allows considerably expanding the scales of application of this method in deposition of protective coatings. 10 Ref., 3 Tables, 6 Figures.
\end{abstract}

$\boldsymbol{K} \boldsymbol{e} \boldsymbol{y} \boldsymbol{w} \boldsymbol{O} \boldsymbol{r} \boldsymbol{s}:$ electric arc metallization, supersonic method, coating, microstructure, phase composition, microhardness

Gas thermal methods of spraying (GTS), first of all gas-flame, plasma, detonation and electric arc metallization (EAM), belong to the basic methods of deposition of protective and restoration coatings, providing the highest economy of metal under the conditions of mass production. Among the mentioned methods the EAM is the simplest, the most efficient and the cheapest one. Thus, according to the existing technical and economic evaluation, the coatings produced using EAM method are 3-10 times cheaper than those produced using other gas thermal methods, like plasma, detonation spraying, etc. [1].

The assortment of wire materials for GTS, including wires of ferrous and non-ferrous metals of solid section, restricted the field of EAM application. Application of flux-cored wires for EAM allowed considerable expanding of scales of application for the given EAM method due to formation of structure with the new physical and chemical properties providing their improved resistance to wear and corrosion. As, for example, is followed from works [2, 3], the use of fluxcored wire systems $\mathrm{Fe}-\mathrm{Cr}-\mathrm{C}$ and $\mathrm{Fe}-\mathrm{Cr}-\mathrm{Al}$ allowed controlling the chemical and phase compositions of coatings within the wide ranges and, consequently, their operation properties.
The authors of these works established that during arc metallization the matrix phase of coating is a solid solution of chromium or chromium with aluminium in $\alpha$ - or $\gamma$-Fe. In the coatings of $\mathrm{Fe}-\mathrm{Cr}$ the $\gamma$-phase prevails, and $\alpha$-phase - in the coating of $\mathrm{Fe}-\mathrm{Cr}-\mathrm{Al}$ system.

The field of application of GTS methods is restricted not always by insufficient strength of bond of coating with the base, and also low mechanical strength of the coating, the reason of which is insufficient energy input to the zone of formation of joining of particles with the base and between each other, that at a short period of hard-phase interaction process proceeding $\left(10^{-3}-10^{-4} \mathrm{~s}\right)$, which controls the formation of forces of adhesion of coating with the base [4], a number of atoms, participating in it, is restricted. At the same time, the realization of GTS process in the air predetermines the formation of oxide films on the sprayed particles and surface of forming coating, which leads to considerable increase of energy for activation of the process of interaction and to embrittlement of sprayed material. In this connection at the present time the modernization of GTS methods is performed due to application of supersonic gas jets (of speeds up to 2-3 M) with increase of kinetic energy of particles being sprayed [5].

On the basis of application of supersonic jets of combustion products of gaseous and liquid fuel 
Table 1. Technological conditions of spraying the coatings using EAM method with flux-cored wire of $1.8 \mathrm{~mm}$ diameter of system $\mathrm{Fe}-\mathrm{Cr}-\mathrm{Al}$

\begin{tabular}{|c|c|c|c|c|c|c|}
\hline Type of installation & Voltage, V & Current, A & $\begin{array}{c}\text { Air } \\
\text { consumption, } \\
\mathrm{m}^{3} / \mathrm{h}\end{array}$ & $\begin{array}{c}\text { Propane } \\
\text { consumption, } \\
\mathrm{m}^{3} / \mathrm{h}\end{array}$ & $\begin{array}{c}\text { Air pressure, } \\
\mathrm{MPa}\end{array}$ & $\begin{array}{c}\text { Spraying } \\
\text { distance, } \mathrm{mm}\end{array}$ \\
\hline \multicolumn{7}{|c|}{ Conventional electric arc spraying } \\
\hline Basic installation EM-14 & $32-34$ & $200-250$ & $120-130$ & - & $0.6-0.7$ & $150-180$ \\
\hline \multicolumn{7}{|c|}{ Modified electric arc spraying } \\
\hline Modified installation EM-14 & $32-34$ & $200-250$ & $120-130$ & - & $0.6-0.7$ & $150-180$ \\
\hline \multicolumn{7}{|c|}{ Supersonic electric arc spraying } \\
\hline Installation PLAZER15-SA & $34-36$ & $160-180$ & 90 & 4.0 & 0.6 & $70-130$ \\
\hline
\end{tabular}

the method of high-speed gas-plasma spraying (HVOF) with design of specialized equipment for its realization was developed [6]. Nowadays HVOF technology finds ever wider practical application due to possibility of producing coatings with high values of density and strength of their adhesion with the base.

The other trend in development of supersonic GTS technologies realized within the joint works of the E.O. Paton Electric Welding Institute and the Gas Institute of the NASU is connected with the development and application of plasmatrons using the combustion products of mixture of air with gas fuel as a working plasma gas [7]. The investigation of properties of the coatings produced in such a way showed the possibility of increasing the strength of adhesion of coatings (up to $150 \mathrm{MPa}$ ), decreasing their porosity and level of oxidation [7].

In the course of development of this trend at the PWI together with the Scientific and Technical Centre PLASER Ltd. and VISP Ltd. the technology was developed and the installation PLAZER15-SA for supersonic electric arc spraying was created $[8,9]$. The technology of supersonic EAM overcomes the basic disadvantages of the electric arc spraying method, connected with the low quality of coatings. The installation provides formation of a supersonic gas jet. The supersonic flow of combustion products of propane-

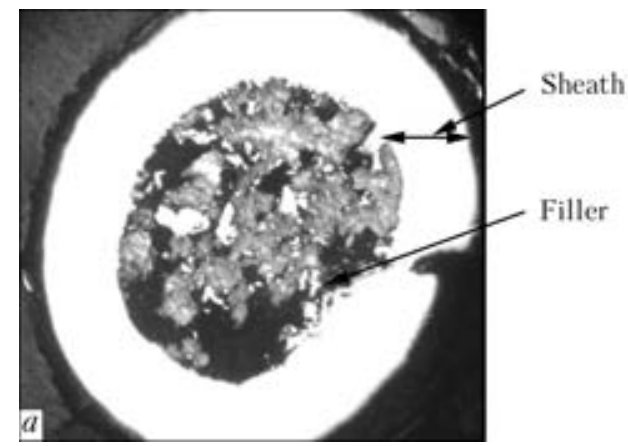

air mixture, directed to the arc zone, disperses the melt and transports the sprayed metal to the base. Using the installation PLAZER 15-SA, the size of molten particles remains by $90 \%$ in the range of $30-80 \mu \mathrm{m}$, which are transformed to the discs of $5-10 \mu \mathrm{m}$ thickness during deformation on the surface. The jet of combustion products almost does not contain oxygen and protects molten metal from oxidation in the arc zone. In the process of deposition of coating the part is heated for not more than up to $150{ }^{\circ} \mathrm{C}$. This guarantees the absence of the part deformation.

The aim of this work is the investigation of peculiarities of structure-phase state of coatings of flux-cored wire of the system $\mathrm{Fe}-\mathrm{Cr}-\mathrm{Al}$ produced using supersonic EAM method. The comparative investigations of coating of flux-cored wire produced using conventional basic installation EM-14, modified basic installation EM-14 with applying secondary air flow and adjustable angle of opening the particles flow and installation PLAZER15-SA for supersonic EAM.

Methods of investigations and initial materials. The investigations of structure of coatings were carried out using methods of metallography (microscope «Neophot-32»), X-ray spectral microanalysis (microanalyser CAMEBAX), X-ray diffraction phase analysis (diffractometer DRON-UM1, monochromatic $\mathrm{Cu} K_{\alpha}$-radiation). The porosity of coatings was determined in the

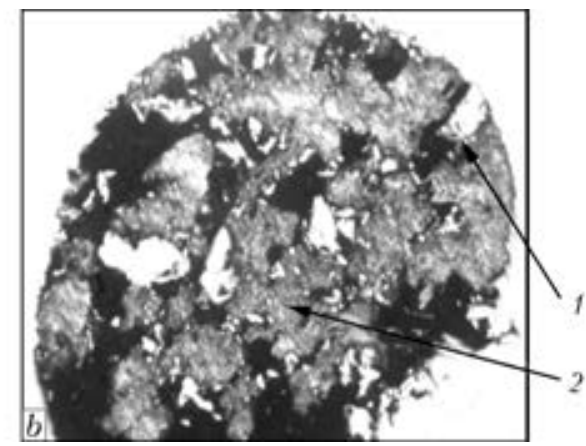

Figure 1. Microstructure $(\times 50)$ of cross section of wire $(a)$, microstructure $(\times 100)$ of filler of $16.6 \mathrm{Fe}, 82.8 \mathrm{Cr}, 0.36 \mathrm{Al}$, $0.2 \mathrm{Mn}(1)$ and $0.36 \mathrm{Fe}, 0.2 \mathrm{Cr}, 99.67 \mathrm{Al}, 0.07 \mathrm{Mn}$ (2) composition 


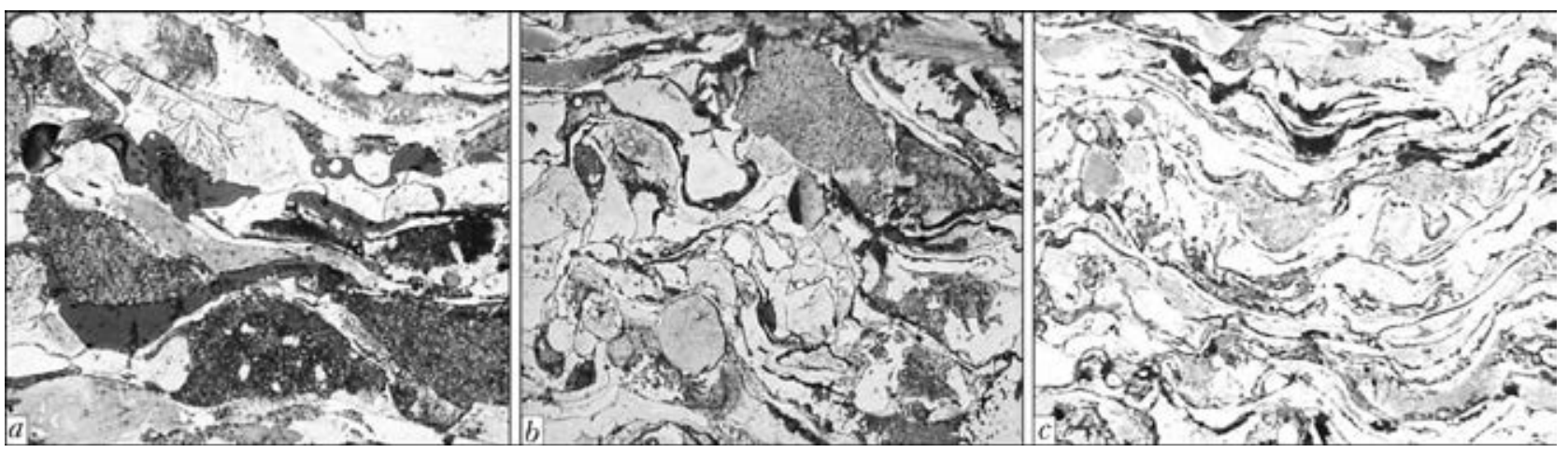

Figure 2. Microstructure $(\times 400)$ of coatings of the $\mathrm{Fe}-\mathrm{Cr}-\mathrm{Al}$ system flux-cored wire produced using different EAM methods: $a$ - conventional; $b-$ modified; $c-$ supersonic spraying

device OMNIMET, microhardness of specimens was measured in the LECO microhardness meter at the indenter loading of $0.25 \mathrm{~N}$.

As a material for spraying the flux-cored wire of the system $\mathrm{Fe}-\mathrm{Cr}-\mathrm{Al}$ was applied. The conditions of coatings spraying are given in Table 1.

Results of work. Investigated was the chemical composition and microstrucutre of initial flux-cored wire and coatings, produced using EAM methods with subsonic and supersonic jets. The flux-cored wire of the system $\mathrm{Fe}-\mathrm{Cr}-\mathrm{Al}$ is composed of a sheath (08kp steel strip) and filler (Figure 1, $a$ ). The composition of a sheath of the flux-cored wire is, wt.\%: $99.2 \mathrm{Fe} ; 0.45 \mathrm{Cr} ; 0.2 \mathrm{Al}$; $0.2 \mathrm{Mn}$. Filler of the wire is composed of mixture of powders $\mathrm{FeCr}$ and $\mathrm{Al}$ with the size of particles of up to $150 \mu \mathrm{m}$. Microstrucutre and composition of filler are presented in Figure 1, $b$.

The analysis of results of metallographic investigations of coatings showed that microstructure at subsonic speeds of air outflow is heterogeneous, coarse-grain, with great number of pores and oxide inclusions. Material of coating is overheated and oxidized, oxide interlayers contain 29-32\% of oxygen, mass fraction of oxygen in lamellas reaches $2.5 \%$ (Figure 2, $a$ ). The particles of spherical shape are also observed, which due

Table 2. Phase composition of coatings produced using different methods of spraying using flux-cored wire of $\mathrm{Fe}-\mathrm{Cr}-\mathrm{Al}$ system

\begin{tabular}{|c|c|c|}
\hline Spraying method & Phase $(a, \mathrm{~nm})$ & $\begin{array}{c}\text { Content, } \\
\text { wt.\% }\end{array}$ \\
\hline \multirow[t]{3}{*}{ Conventional } & S.s. of $\mathrm{Cr}$ and $\mathrm{Al}$ in $\alpha-\mathrm{Fe}(0.2879)$ & 53.36 \\
\hline & S.s. of $\mathrm{Cr}$ and $\mathrm{Al}$ in $\gamma$-Fe $(0.3627)$ & 23.70 \\
\hline & $\mathrm{Al}_{2} \mathrm{O}_{3}(0.7916)$ & 22.93 \\
\hline \multirow{3}{*}{$\begin{array}{l}\text { Conventional } \\
\text { modified }\end{array}$} & S.s. of $\mathrm{Cr}$ and $\mathrm{Al}$ in $\alpha$-Fe $(0.2875)$ & 57.08 \\
\hline & S.s. of $\mathrm{Cr}$ and $\mathrm{Al}$ in $\gamma_{1}-\mathrm{Fe}(0.3677)$ & 8.58 \\
\hline & S.s. of $\mathrm{Cr}$ and $\mathrm{Al}$ in $\gamma_{2}-\mathrm{Fe}(0.36305)$ & 34.34 \\
\hline \multirow[t]{3}{*}{ Supersonic } & S.s. of $\mathrm{Cr}$ and $\mathrm{Al}$ in $\alpha-\mathrm{Fe}(0.2870)$ & 22.39 \\
\hline & S.s. of $\mathrm{Cr}$ and $\mathrm{Al}$ in $\gamma_{1}-\mathrm{Fe}(0.3677)$ & 28.05 \\
\hline & S.s. of $\mathrm{Cr}$ and $\mathrm{Al}$ in $\gamma_{2}-\mathrm{Fe}(0.3633)$ & 49.56 \\
\hline
\end{tabular}

to a low speed of flying managed to cool down before their collision with the surface being sprayed (Figure 3 ).

The coating, produced using the modified basic installation applying the additional air flow and adjustable angle of opening the particles flow, is less oxidized. In the lamellas and oxide interlayers the mass fraction of oxygen amounts, respectively, to $1.6-1.8$ and $29-30 \%$. The thickness of lamellas $\delta$ for these coatings is the same as under the conventional subsonic conditions and equal to $10-30 \mu \mathrm{m}$ (Figure 2, b), porosity of coatings amounts to $2-3 \%$.

In transition to supersonic air-gas EAM method, with increase in the rate of air flow, the speed of flying particles increases and microstructure of the produced coating is subjected to considerable changes. Combination of small size of sprayed particles with their high speeds at the moment of collision with the base surface leads to high speeds of their material cooling. In general, the particles have lamella-like shape and are subjected to significant deformations. The inclusions of globular particles are not observed. Thin

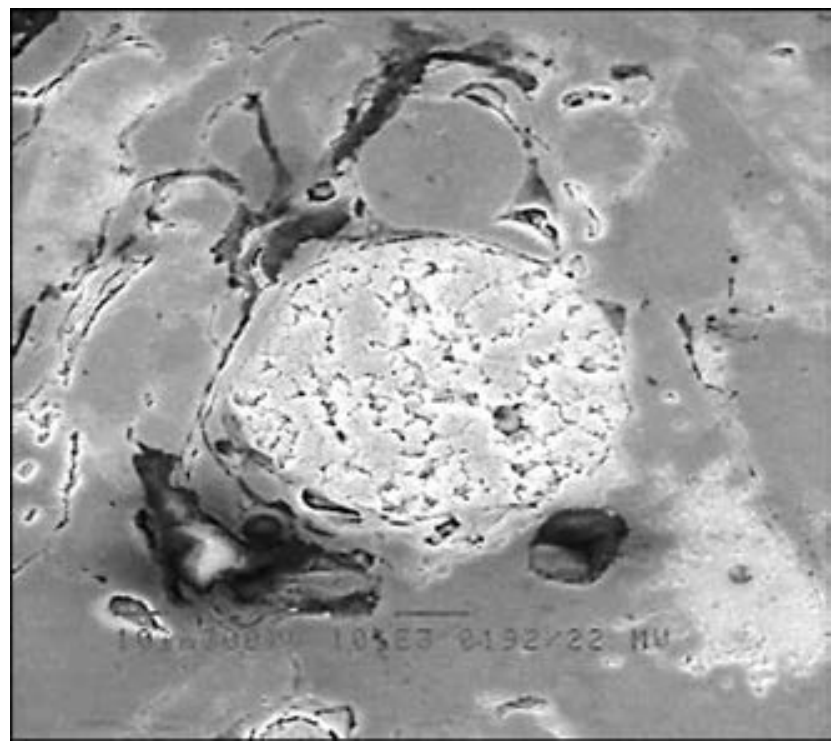

Figure 3. Appearance of single particle in the $\mathrm{Fe}-\mathrm{Cr}-\mathrm{Al}-$ system coating in EAM $(\times 1000)$ 

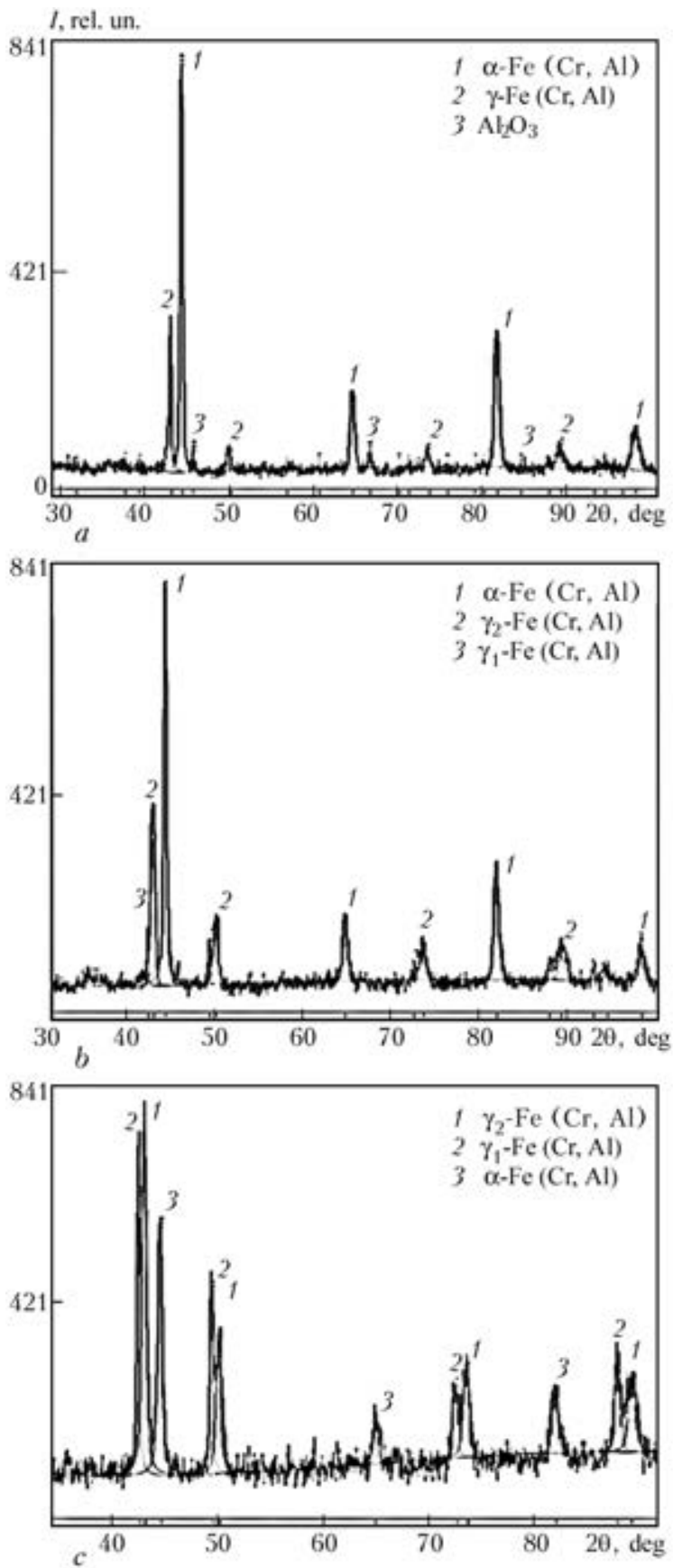

Figure 4. Diffractograms of the $\mathrm{Fe}-\mathrm{Cr}-\mathrm{Al}$ coatings produced using different EAM methods: $a-$ conventional; $b-$ modified; $c$ - supersonic spraying

oxide interlayers are noted. Across the whole thickness the coatings have homogeneous thinlamellar structure, which evidences of the process stability. In the coatings deposited at supersonic air-gas spraying, $\delta=5-10 \mu \mathrm{m}$ (Figure $2, c$ ). Porosity of the structure is decreased and amounts to $0.4 \%$.

It follows from the analysis of results of X-ray spectral microanalysis and diffractograms of the coatings (Table 2, Figures 4 and 5) that all the investigated coatings produced using methods of conventional subsonic EAM, modified and supersonic EAM contain solid solution (S.s.) of alu-
Table 3. Composition of the $\mathrm{Fe}-\mathrm{Cr}-\mathrm{Al}$ system coating in different EAM methods

\begin{tabular}{|c|c|c|c|c|}
\hline \multirow{2}{*}{ Coating area } & \multicolumn{4}{|c|}{ Content of elements in different coating areas, wt.\% } \\
\hline & $\mathrm{Al}$ & $\mathrm{Cr}$ & $\mathrm{Fe}$ & $\mathrm{O}$ \\
\hline \multicolumn{5}{|c|}{ Subsonic conventional spraying } \\
\hline $\begin{array}{c}\text { Grey } \\
\text { lamellas }\end{array}$ & $5.0-5.2$ & $14.0-15.0$ & 78 & $1.9-2.5$ \\
\hline $\begin{array}{c}\text { White } \\
\text { lamellas }\end{array}$ & $3.5-4.0$ & $16.8-17.1$ & 80 & 0 \\
\hline $\begin{array}{c}\text { Oxide } \\
\text { interlayers }\end{array}$ & $35.0-39.0$ & $6.0-7.0$ & 30 & $29.0-32.0$ \\
\hline \multicolumn{5}{|c|}{ Subsonic modified spraying } \\
\hline $\begin{array}{c}\text { Grey } \\
\text { lamellas }\end{array}$ & $6.0-6.2$ & $15.0-15.4$ & $75-76$ & $1.6-1.8$ \\
\hline $\begin{array}{l}\text { White } \\
\text { lamellas }\end{array}$ & 5.9 & $13.0-14.5$ & 80 & 0 \\
\hline $\begin{array}{c}\text { Oxide } \\
\text { interlayers }\end{array}$ & $37.0-39.0$ & $5.0-6.0$ & $26-27$ & $29.0-30.0$ \\
\hline \multicolumn{5}{|c|}{ Supersonic spraying } \\
\hline $\begin{array}{c}\text { Grey } \\
\text { lamellas }\end{array}$ & $4.8-5.6$ & $16.9-20.5$ & $75-76$ & $1.2-1.3$ \\
\hline $\begin{array}{c}\text { White } \\
\text { lamellas }\end{array}$ & $6.0-6.2$ & $20.0-20.5$ & $75-73$ & $0-0.4$ \\
\hline $\begin{array}{c}\text { Oxide } \\
\text { interlayers }\end{array}$ & $18.0-23.0$ & $10.6-14.0$ & $50-55$ & $11.5^{-17.0}$ \\
\hline
\end{tabular}

minium and chromium in $\alpha-\mathrm{Fe}$ (BCC lattice with atomic radius $a=0.2879 \mathrm{~nm}$ ), and solid solutions of aluminium and chromium in $\gamma$-Fe with FCC lattice and different content of these elements. According to the data of X-ray spectral microanalysis at conventional arc and modified metallization a solid solution of chromium with aluminium in $\alpha-\mathrm{Fe}$ is prevailed, while in case of supersonic EAM the $\gamma$-phase is the main phase in the coatings. At supersonic and modified EAM the phase $\gamma$-Fe component with changed parameters exists in two modifications, namely: $\gamma_{1}-\mathrm{Fe}(\mathrm{Cr}, \mathrm{Al})$ with $a=0.3677 \mathrm{~nm}$, and $\gamma_{2}-\mathrm{Fe}(\mathrm{Cr}, \mathrm{Al})$ with $a=$ $=0.3633 \mathrm{~nm}$ (Figure 4, b,c).

The difference in values of parameters of lattice of $\gamma_{1}$-Fe and $\gamma_{2}$-Fe evidences of different content of alloying elements. The distribution of alloying elements was investigated on the sections, approximately in the central part of coatings, in the depth, perpendicularly to the interface of coatings with the base. The content of elements in the coating is given in Table 3 and Figure 5. It was established that maximum concentration of chromium in the Fe-based solid solution in lamellas of coatings, produced at conventional and modified spraying, amounts to $16.8-17.1$ and 15.0-15.4 wt.\% respectively, under the same conditions the content of aluminium amounts ap- 

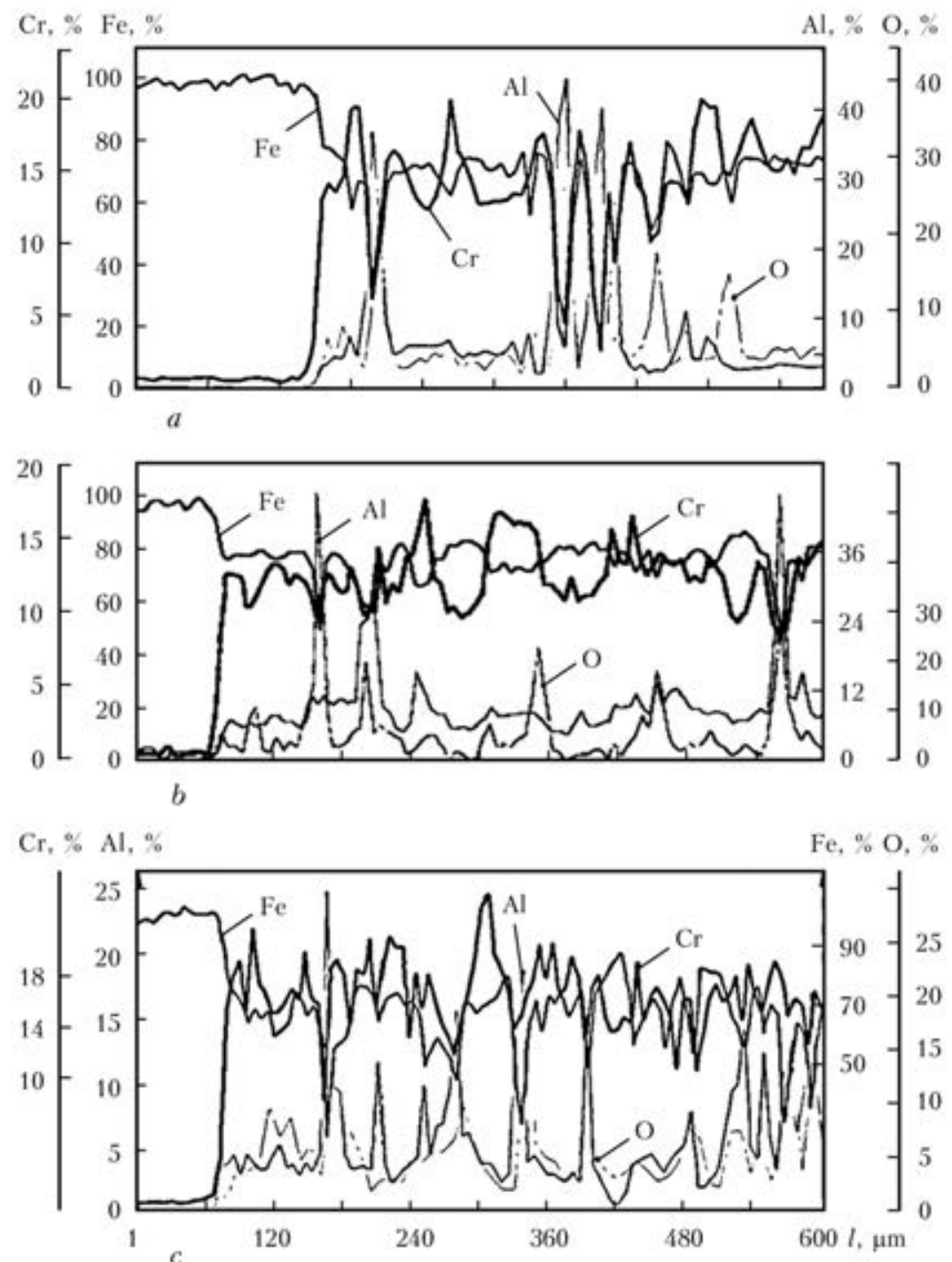

Figure 5. Distribution of alloying elements across the thickness of coatings produced using different EAM methods: $a-$ conventional; $b-$ modified; $c-$ supersonic

proximately from 4.0 to $6.2 \%$. Moreover, in the process of spraying the aluminium interacts with oxygen, the inclusions are formed on the base of $\mathrm{Al}_{2} \mathrm{O}_{3}$ containing 35-39 wt.\% $\mathrm{Al}$ and 2932 wt.\% O.

While using supersonic jets the turbulent mode of jets flowing out transfers to laminar one, thus decreasing the air entry to the mixture and simultaneously increasing the rate of particles due to increase in speed of gas jet.

During supersonic spraying the amount of chromium and aluminium solved in iron increases, maximum concentration of chromium in lamellas reaches 20.0-20.5 wt.\%. A solid solution of such concentration is characterized by a high resistance to oxidation by air oxygen. The level of oxidation of sprayed coating is considerably decreased. In lamellas the content of oxygen is about $1 \%$.

If to compare the obtained results of X-ray diffraction phase analysis and X-ray spectral mi-

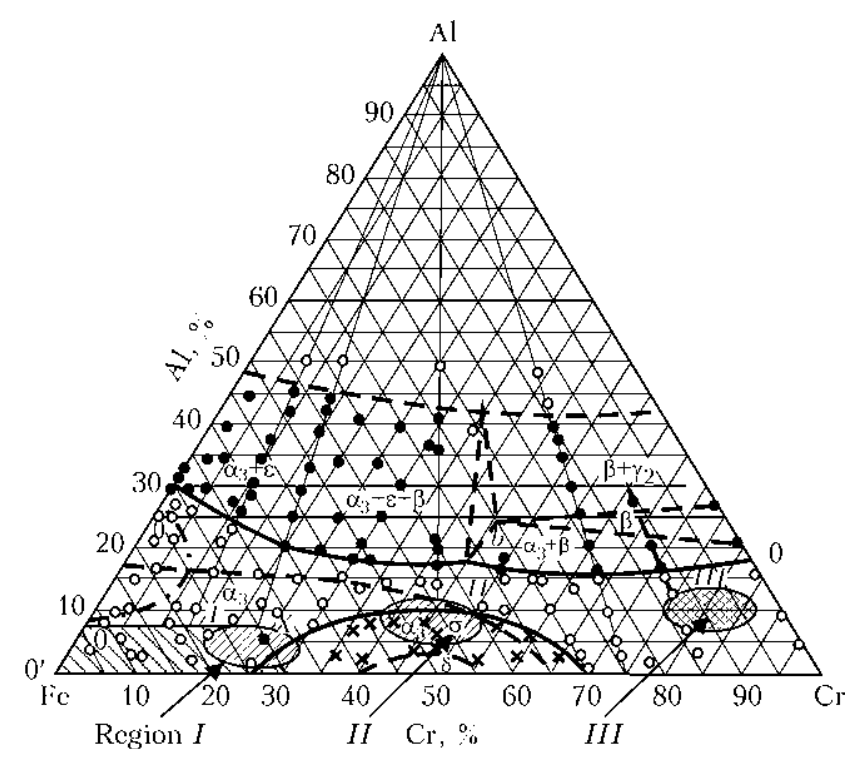

Figure 6. Diagram of $\mathrm{Fe}-\mathrm{Cr}-\mathrm{Al}$ phase equilibrium (for designations see the text) 
croanalysis of the coating, produced at supersonic EAM, with the region of ternary diagram $\mathrm{Fe}^{-}$ $\mathrm{Cr}-\mathrm{Al}$ (Figure 6) by the chemical composition corresponding to the composition of investigated coating, then the coating gets to the designated high-temperature region $I$, which provides heat resistance up to the temperature of $1350{ }^{\circ} \mathrm{C}$ [10].

Thus, at the increased content of up to $20.5 \% \mathrm{Cr}$ and $6.2 \% \mathrm{Al}$ in the Fe solid solution, the heat resistance of coatings produced in supersonic EAM up to $1350{ }^{\circ} \mathrm{C}$ is provided.

Comparison of values of microhardness of coatings of flux-cored wire, sprayed using different methods, shows that microhardness of coating produced in conventional EAM is changed in the limits from 1930 to $4200 \mathrm{MPa}$, microhardness of coating produced using modified installation is changed from 2540 to $5100 \mathrm{MPa}$. Maximum microhardness belongs to the supersonic coatings where the range of values is in the limits of 3900$6100 \mathrm{MPa}$, which can be connected with the increase of chromium content in the Fe-based solid solution.

\section{Conclusions}

As a result of carried out investigations it was found that the process of electric arc air-gas supersonic metallization as compared to the conventional GTS methods allows producing coatings with more homogeneous and fine-grain structure. The thickness of lamellas is 2-3 times decreased due to a small period of contact of molten particles with atmosphere and their high speed, the oxidation of material being sprayed is $2-3$ times decreased, and the porosity is $3-5$ times decreased. Microhardness of coating produced in supersonic EAM exceeds microhardness of sub- sonic coatings approximately by $30-50 \%$. Using $\mathrm{X}$-ray spectral microanalysis and X-ray diffraction phase analysis it was established that strengthening of coatings is provided by formation of oversaturated solid solution of iron with increased content of chromium of up to $20.5 \mathrm{wt} . \%$ and aluminium of up to $6.2 \mathrm{wt} . \%$. The flux-cored wire of the system $\mathrm{Fe}-\mathrm{Cr}-\mathrm{Al}$ allows producing the structure with content of austenite of up to 80 wt.\% in the coatings.

1. Boronenkov, V.N., Korobov, Yu.S. (2012) Bases of arc metallizing. Physical-chemical principles. Ekaterinburg: UralGU.

2. Pokhmursky, V.I., Student, M.M., Dovgunyk, V.M. et al. (2003) Structure and tribotechnical characteristics of coatings produced by electric arc metallizing using flux-cored wires. The Paton Welding J., 8, 12-16.

3. Borisova, A.L., Kajda, T.V., Mits, I.V. (1995) Structure and properties of coatings on ferrochrome and ferrochromealuminium base, produced by electric arc metallizing using flux-cored wires. Avtomatich. Svarka, 6, 3-6.

4. Kudinov, V.V. (1977) Plasma coatings. Moscow: Nauka.

5. Borisov, Yu.S., Petrov, S.V. (1995) Application of supersonic jets in thermal spraying technology. Avtomatich. Svarka, 1, 41-44.

6. Frolov, V.A., Poklad, V.A., Ryabenko, B.V. et al. (2006) Technological peculiarities of methods of supersonic thermal spraying (Review). Svarochn. Proizvodstvo, 11, 38-47.

7. Petrov, S.V., Karp, I.N. (1993) Plasma air-gas spraying. Kiev: Naukova Dumka.

8. Korzhik, V.N., Krivtsun, I.V., Petrov, S.V. et al. (2009) New technology «Plazer» for renovation of railway parts. Remont, Vosstanovlenie, Modernizatsiya, 1, 20-22

9. Petrov, S.V., Korzhik, V.N. (2011) Plazer15-SA installation for electric arc supersonic spraying. Svarshchik, 1, 117-121.

10. Hudremont, E. (1966) Special steels. Moscow: Metallurgiya.

Received 04.07.2013 